\title{
Factors associated with the Career Preference of 6-Year Doctor of Pharmacy (Pharm.D) Students in Korea: a National Survey
}

\author{
Ah Rahm Han, MiHyun Gil, SeungJin Bae \\ Department(s) and Institution(s) College of Pharmacy, Ewha Womans University, Ewhayeodae Gil, Seodaemungu, Seoul, 120-750, \\ KOREA.
}

\begin{abstract}
Background: To expand the pharmacist's role beyond dispensing prescription drugs in community pharmacies, a 6-year doctor of pharmacy (PharmD) programme was introduced in 2011 and replaced the traditional 4-year bachelor pharmacy programme in Korea. This study investigated the career preference of students at newly implemented 6-year PharmD programmes in Korea. Methods: A cross-sectional survey was administered to PharmD students enrolled in all pharmacy schools in Korea as of July 2014. Data analyses were mainly descriptive. Results: Of 6,679 total pharmacy students in Korea, $2,490(37.3 \%)$ responded, and after excluding incomplete responses, 2,361 total responses were included for the analysis. The hospital pharmacy was most preferred by respondents $(30.5 \%)$, followed by the pharmaceutical industry $(21.8 \%)$, community pharmacy $(19.9 \%)$, further education $(16.1 \%)$, and the public sector $(11.7 \%)$. The gender divergence was significant, with females preferring the hospital pharmacy $138.3 \%$ versus $16.1 \%$ males; $\mathrm{p}<0.0001)$, whereas males preferring the community pharmacy $(29.3 \%$ versus $14.9 \%$ females; $p<0.0001)$. The key factor related to selecting a hospital pharmacy, government sector, and further education was the student's aptitude $136.4 \%$, $37.7 \%$, and $38.4 \%$, respectively), whereas the key factor for selecting a community pharmacy was a competitive salary $(44.4 \%)$. Conclusions: The newly implemented 6 -year PharmD students chose hospital pharmacy as the most preferred career path, and their aptitude was the key factor related to their career preference.Career preference was evenly distributed across diverse career paths, which shows clear contrasts with their predecessors who have4-year bachelors of pharmacy degrees.
\end{abstract}

Key words: Career, Doctor of pharmacy program, Pharmacy students, Korea.

\section{INTRODUCTION}

With the introduction of the World Trade Organization (WTO)'s Doha agenda, which aims to open and clarify rules on domestic regulations, domestic pharmacists may face competition from foreign pharmacists. To keep up with international trends and enhance domestic pharmacists' competency, the Korean Pharmacists' Society (KPS) had voiced the need to implement a 6-year doctor of pharmacy (Pharm D)programme instead of the status quo 4-year bachelor of pharmacy programme. ${ }^{1}$ Under the 4-year pharmacy programme, most of pharmacists were working in community pharmacy (73.5\%), followed by hospital pharmacies $(11.7 \%)$, pharmaceutical industry $(3 \%)$, and the government sector $(0.37 \%) .^{2}$ The roles of community pharmacists were mainly focused on dispensing prescriptions. However, a strong demand for pharmacists has been demonstrated in the pharmaceutical industry for such areas as $R \& D$ and market access
Submission Date : 21-03-2016 Revision Date : :12-05-2016 Accepted Date : :08-06-2016

DOI: 10.5530/ijper.50.3.2 Correspondence: Seung Jin Bae, Sc.D. College of Pharmacy, Ewha Womans University, 52 Ewhayeodae Gil, Seodaemungu, Seoul, 120-750, KOREA. Tel: 82-2-3277-3056; Fax: 82-2-6710-5836; E-mail: sjbae@ewha.ac.kr

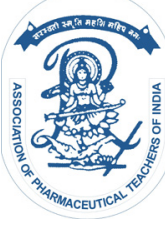

www.ijper.org 
(regulatory affairs and pricing and reimbursement) and the government sector such as the Korean Ministry of Food and Drug Administration and Health Insurance Review and Assessment service, yet the demand is frequently unmet, ${ }^{3,4}$ The chronic shortage of pharmacists, as well as the pharmacy school's curriculum, which had not changed since the 1960s, have been blamed as key factors as to why pharmacists' primarily focus their careers on community pharmacies. ${ }^{5}$ The shortage is likely to be aggravated due to the ageing population and the expansion of pharmacists' roles, which exceeds dispensing prescription drugs. ${ }^{6,7}$

The 6-year PharmD programme has been newly implemented since 2011 and replaces the 4-year program, and social and administrative pharmacy and clinical pharmacy has also been newly introduced in the curriculum and included in the Korean Pharmacist Licensure exam. Additionally, the number of pharmacy schools has increased from 20 to 35, which results in an increase of annual pharmacy graduates from approximately 1200 to $1700 .{ }^{8}$ The 6-year PharmD programme is a $2+4$ system, unlike the 4-year bachelor of pharmacy programme in which high school graduates are eligible to apply; the 6-year programme requires undergraduates to have at least two years of college education and to take an entrance exam called the PEET (Pharmacy Education Eligibility Test), which covers chemistry, biology and physics. The admitted 6-year PharmD students receive four years of pharmacy education at pharmacy school and are eligible to take the national pharmacist license exam upon the completion of 4-years of education at the pharmacy school. ${ }^{9}$

With the introduction of the 6-year PharmD program, pharmacy students are likely to be more diverse than the previous 4-year program, and their job market opportunities may be less promising because of the increased number of pharmacists. The entering pharmacy students have various college majors, and their age varies widely, with some who graduated from college with working experience, whereas others have only finished 2-years of college education. This diversity was not observed with the previous 4-year program, in which most entering students had only graduated from high school without previous college experience. Therefore, their preferred career path may be different from that of 4-year graduates. Moreover, unlike the 4-year programme in which most pharmacists had no difficulty in finding reasonable jobs, the number of pharmacy students has significantly increased with implementation of the 6-year PharmD program, causing some concerns of an oversupply of pharmacists, particularly if the majority intend to work at community pharmacies. This study sought to investigate the career preferences of 6-year PharmD students in Korea. Specifically, we describe the personal characteristics (such as age, gender, location of schools, previous majors) related to the career preferences and examine potential factors associated with the choice of career by conducting a national survey of pharmacy students.

\section{METHODS}

\section{Overview}

Since the launch of the 6-year PharmD programme in 2011, a total of 6,679 pharmacy students $\left(1^{\text {st }}\right.$ year 1,693; $2^{\text {nd }}$ year 1,$698 ; 3^{\text {rd }}$ year 1,$695 ; 4^{\text {th }}$ year 1,593$)$ have entered pharmacy school as of 2014.To survey all pharmacy students in Korea, we contacted the pharmacy student councils of all 35 pharmacy schools in Korea and asked them to distribute the survey questionnaire from July $30^{\text {th }} 2014$ until August $13^{\text {th }}$. A web-based survey called SurveyMonkey ${ }^{\circledR}$, which sendsurveys via mobile, web, and social media, was used to collect the questionnaire. The purpose and the nature of the study were provided to the student councils of all 35 pharmacy schools, and only students who consented to the collection and analysis of data were invited to participate. 6 reminders were sent to 35 pharmacy school student councils during the survey period to encourage participation. All information collected from the survey was kept confidential.

\section{Survey questionnaire}

\section{Focus group interview}

The questionnaire was developed based on a literature review, ${ }^{10-12}$ and two focus group interviews (FGI) were performed, which identified key questions regarding pharmacists' future career preference. One FGI consisted of three pharmacy students, and the other FGI consisted of four pharmacists working in the pharmaceutical industry, a community pharmacy, a hospital pharmacy, and the government sector. The FGI was conducted to make sure that the questions were relevant to the objectives of our study, clearly described, and could be answered within 10 minutes.

\section{Questionnaire development}

The survey consisted of nine questions, seven of which were asked to all respondents and two of which were asked to specific subgroups of respondents. Specifically, the demographic characteristics, including gender, ageat the time they entered pharmacy school (in ranges), geographic location of the pharmacy schools (5 metropolitan areas), student grades in the programme (year one to four), and previous education major (natural science, engineering, health/medicine, or others) were 
asked to all respondents. For male students, additional questions regarding the completion of military service (yes/no) was asked because mandatory military service may be waived for students who pursue a master's degree program, which could influence the career preference of male students. The career preference questions investigated the preferred career immediately after graduation (hospital pharmacy, community pharmacy, pharmaceutical industry, government sector, or pursing a further degree as a full-time student), and students were asked to identify the most preferred one. The government sector was defined as government-policy related roles, such as related affairs at the Korean National Health Insurance or regulatory affairs at the Korean Ministry of Food and Drug Administration. Further education was defined as full-time graduate students who were interested in careers in research or academia.

To determine whether education at pharmacy school influenced students' choice of career path, $4^{\text {th }}$ year pharmacy students were additionally asked their preferred career path before they were admitted to pharmacy school because they have finished most of the curriculum at pharmacy school, including mandatory practicum/ internship.

Factors influencing the choice of future career path were presented (future opportunities for learning and development, competitive salary, friendly work environment, student aptitude, or comprehensive benefit, such as generous pension at the time of retirement), ${ }^{13}$ and students were asked to select the most appropriate factor. All questions were presented as closed-ended (namely, check the box), such that students could finish the survey within 10 minutes. We also provided an "other" option such that respondents could freely express their opinions in case their preferred answer was not presented.

Pilot study

The questionnaire was pilot tested by 5 student councils, and they determined whether the choices provided in the questions were mutually exclusive and exhaustive, as well as the clarity of the questions. The questions were amended if 2 or more of the councils suggested changing the questions/selections. The internal validity of the questionnaire was assessed by the consistency of the questionnaire, for example, a self-identified female student who answered "yes" regarding military service was excluded due to the lack of internal validity.

\section{Consent form and ethical review}

The institutional review board (IRB) review was not a prerequisite for our survey because recipient personal characteristics, which could trace a recipient's identity (such as date of birth/recipient's exact age, or place of birth), were not included in the analysis. We assured the anonymity of the respondents throughout the study. Additionally, although all students were invited to participate, only recipients who provided written consent for participation in the survey were included in the analysis; therefore, the IRB process was waived.

\section{Data collection}

A web-based survey called Survey Monkey ${ }^{\circledR}$ (Palo Alto, CA, USA), which sends surveys via mobile, web, and social media, was used to collect the questionnaire. The 6-year PharmD students from 35 pharmacy schools were invited to participate through their student councils, who sent the invitation through the students' main contact information. Students could only participate with the invitation, and after the invitation was used for the survey, the invitation could not be used for another survey. Therefore, student's could only participate once.

The survey was anonymous; however, the codified IP addresses were collected. Therefore, some of the completed questions could be traced back to the individuals after de-codifying the address, although others, which were conducted on public PCs, could not be traced. To increase the response rate, we sent reminders a total of 6 times, provided financial incentives (mobile gift certificate), and notified students that the survey required less than 10 minutes to complete. ${ }^{14}$

\section{Statistical Analyses}

The collected raw data were recorded in a Microsoft Excel $^{\mathbb{B}}$ spread sheet by two independent researchers. Incomplete surveys and those that lacked internal validity (for example, a self-identified female student who answered military service) were excluded, and a consensus regarding the exclusion criteria was reached by two researchers. The association between demographic characteristics and career preference was analysed by a $\chi^{2}$ test, and the results were deemed statistically significant at a $\mathrm{p}$ value less than 0.05 . When the cell size was less than 5 , Fisher's exact test was used instead of the $\chi^{2}$ test. The strength of associations between demographic characteristics and the likelihood of selecting a specific career path was analysed based on multivariate logistic regressions, with the specific career path being binary dependent variables (hospital yes/no; community pharmacy yes/ no; pharmaceutical industry yes/no). All analyses were performed using SAS version 9.3 (SAS Institute Inc, Cary, NC, USA). 


\section{RESULTS}

\section{Demographic characteristicsof the respondents}

Of 6,679 total pharmacy students in Korea, 2,490 (37.3\%) participated in the survey, and after excluding 129 surveys, which lacked internal validity or with incomplete answers, a total of 2,361 responses (35.3\% of total responses) were included for the analysis.

Demographic characteristics of the respondents are presented in Table 1 . Most of the respondents were females (1,534 respondents, $65.0 \%)$, aged 19-24 years $(1,798$ respondents, $76.2 \%)$, enrolled in pharmacy schools located in the Seoul/Kyungki area $(1,275$ respondents, $54.0 \%$ ), and majored in natural science $(1,278$ respondents, $54.1 \%)$. The $1^{\text {st }}, 2^{\text {nd }}, 3^{\text {rd }}, 4^{\text {th }}$ year students represented $31.2 \%, 25.0 \%, 24.4 \%$, and $19.4 \%$ of the sample, respectively.

\section{Preferred career based on the respondents' demographic characteristics}

Of 2,361 pharmacy students who responded, Table 2 shows that hospital pharmacy was the most preferred (30.5\%, 720 respondents) setting, followed by the pharmaceutical industry (21.8\%), community pharmacy (19.9\%), pursuing a further degree (16.1\%), and government sector (11.7\%). A subgroup analysis demonstrated a significant difference for gender variable. After controlling for other variables, a multivariate logistic regression also showed that female respondents were 3.397 times more likely to prefer a hospital pharmacy (odds ratio $(\mathrm{OR})=$ 3.397, $\mathrm{p}<0.0001)$ compared to their male counterparts, after controlling for other variables. (Supplementary Table 2).

There was an association between the age of respondents and their career preference. More than half (64.1\%) of the older respondents (aged older than 30) preferred community pharmacy for the future career; however, it was selected by only $14.0 \%$ of their younger counterparts (aged 19-24, $\mathrm{p}<0.0001$ ). The proportion of respondents who wanted to pursue further education showed the opposite trend, with younger respondents (aged 19-24) showing a highest proportion (19.5\%) and respondents aged 30 and older showing the lowest proportion $(1.1 \%, \mathrm{p}<0.0001)$.

Previous major, years of pharmacy education, and geographic location were also significantly associated with career preferences (Table 2).

\section{Factors affecting career choices}

Factors influencing the choice of career varied significantly, with competitive salary being the most critical factor for selecting community pharmacy (44.5\%), whereas aptitude was most important for students who selected hospital pharmacy (36.4\%), pharmaceutical industry $(37.5 \%)$, further education $(58.4 \%)$, and the government sector $(37.7 \%, \mathrm{p}<0.0001$, Table 3$)$.

When we asked seniors ( $4^{\text {th }}$ year students) who had nearly finished pharmacy schools to recall and select their preferred career before they entered pharmacy school, the preference for hospital pharmacy increased after education ( 21.9 vs. $35.4 \%$ ), whereas preference for the government sector ( $8.8 \%$ vs. $4.2 \%)$ and further education $(21.7 \%$ vs. $16.6 \%)$ decreased after they had nearly completed pharmacy school ( $\mathrm{p}<0.0001$, data not shown).

\section{DISCUSSION}

The national survey, which represented $35.3 \%$ of total pharmacy students in Korea, demonstrated that unlike

\begin{tabular}{|c|c|c|}
\hline Characteristics & Number & $\%$ \\
\hline \multicolumn{3}{|l|}{ Gender } \\
\hline Male & 827 & 35.0 \\
\hline Female & 1,534 & 65.0 \\
\hline \multicolumn{3}{|l|}{ Entrance age } \\
\hline $19-24$ & 1,798 & 76.2 \\
\hline $25-29$ & 471 & 19.9 \\
\hline $30>$ & 92 & 3.9 \\
\hline \multicolumn{3}{|l|}{ Previous major } \\
\hline Science & 1,278 & 54.1 \\
\hline Engineering & 672 & 28.5 \\
\hline Health/Medical & 187 & 7.9 \\
\hline Other ${ }^{a}$ & 224 & 9.5 \\
\hline \multicolumn{3}{|l|}{ Grade } \\
\hline $1^{\text {st }}$ & 737 & 31.2 \\
\hline $2^{\text {nd }}$ & 590 & 25.0 \\
\hline $3^{\text {rd }}$ & 577 & 24.4 \\
\hline $4^{\text {th }}$ & 457 & 19.4 \\
\hline \multicolumn{3}{|l|}{$\begin{array}{c}\text { Geographic location of } \\
\text { pharmacy school }\end{array}$} \\
\hline Seoul/Kyungki & 1,275 & 54.0 \\
\hline Gangwon & 92 & 3.9 \\
\hline Chungcheong & 263 & 11.1 \\
\hline Jeolla & 272 & 11.5 \\
\hline Gyeongsang & 459 & 19.4 \\
\hline Total & 2,361 & 100.0 \\
\hline
\end{tabular}

${ }^{a}$ Other includes education, liberal arts, social science, art, human ecology, and agricultural science. 


\begin{tabular}{|c|c|c|c|c|c|c|c|c|}
\hline Characteristics & Total & $\begin{array}{c}\text { Community } \\
\text { Pharmacy }\end{array}$ & Hospital & $\begin{array}{l}\text { Pharmaceutical } \\
\text { Industry }\end{array}$ & $\begin{array}{l}\text { Public } \\
\text { Sector }\end{array}$ & $\begin{array}{l}\text { Further } \\
\text { Education }\end{array}$ & DFc & P valuea \\
\hline \multicolumn{9}{|l|}{ Gender } \\
\hline Male & $827(100)$ & 242 (29.3) & 133(16.1) & $183(22.1)$ & 68 (8.2) & $201(24.3)$ & 4 & $<0.0001$ \\
\hline Female & $1,534(100)$ & $228(14.9)$ & $587(38.3)$ & $332(21.6)$ & $\begin{array}{c}208 \\
(13.6)\end{array}$ & $179(11.7)$ & & \\
\hline \multicolumn{9}{|l|}{ Age } \\
\hline $19-24$ & $1798(100)$ & $251(14.0)$ & $541(30.1)$ & $436(24.2)$ & $\begin{array}{c}219 \\
(12.2)\end{array}$ & 351 (19.5) & 8 & $<0.0001$ \\
\hline $25-29$ & $471(100)$ & $160(34.0)$ & $160(34.0)$ & $72(15.3)$ & $51(10.8)$ & $28(5.9)$ & & \\
\hline $30 \geq$ & $92(100)$ & $59(64.1)$ & $19(20.7)$ & $7(7.6)$ & $6(6.5)$ & $1(1.1)$ & & \\
\hline \multicolumn{9}{|l|}{ Previous major } \\
\hline Science & $1,278(100)$ & $222(17.4)$ & $395(30.9)$ & $281(22.0)$ & $\begin{array}{c}163 \\
(12.8)\end{array}$ & 217 (17.0) & 12 & 0.0033 \\
\hline Engineering & $672(100)$ & $152(22.6)$ & $182(27.1)$ & $162(24.1)$ & $69(10.3)$ & $107(15.9)$ & & \\
\hline Health/Medical & $187(100)$ & 41 (21.9) & $73(39.0)$ & $30(16.0)$ & $23(12.3)$ & $20(10.7)$ & & \\
\hline Other $b$ & $224(100)$ & $55(24.6)$ & $70(31.3)$ & $42(18.8)$ & $21(9.4)$ & 36 (16.1) & & - \\
\hline \multicolumn{9}{|c|}{ Grade at pharmacy school } \\
\hline $1^{\text {st }}$ & $737(100)$ & $119(16.1)$ & $206(28.0)$ & $163(22.1)$ & $\begin{array}{c}118 \\
(16.0)\end{array}$ & $131(17.8)$ & 12 & $<0.0001$ \\
\hline $2^{\text {nd }}$ & $590(100)$ & $107(18.1)$ & $169(28.6)$ & $138(23.4)$ & $81(13.7)$ & $95(16.1)$ & & \\
\hline $3^{\text {rd }}$ & $577(100)$ & $134(23.2)$ & $183(31.7)$ & $124(21.5)$ & $58(10.1)$ & $78(13.5)$ & & \\
\hline $4^{\text {th }}$ & $457(100)$ & $110(24.1)$ & $162(35.4)$ & $90(19.7)$ & $19(4.2)$ & $76(16.6)$ & & \\
\hline \multicolumn{9}{|c|}{ Geographic location of pharmacy school } \\
\hline Seoul/Kyungki & $1,275(100)$ & $159(12.5)$ & $369(28.9)$ & $332(26.0)$ & $\begin{array}{c}165 \\
(12.9)\end{array}$ & $250(19.6)$ & 16 & $<0.0001$ \\
\hline Gangwon & $92(100)$ & $22(23.9)$ & $28(30.4)$ & $21(22.8)$ & $12(13.0)$ & $9(9.8)$ & & \\
\hline Chungcheng & $263(100)$ & $42(16.0)$ & $88(33.5)$ & $58(22.1)$ & $27(10.3)$ & $48(18.3)$ & & \\
\hline Jeolla & $272(100)$ & $98(36.0)$ & $82(30.1)$ & $34(12.5)$ & $29(10.7)$ & $29(10.7)$ & & \\
\hline Gyeongsang & $459(100)$ & $149(32.5)$ & 153 (33.3) & 70 (15.3) & $43(9.4)$ & $44(9.6)$ & & \\
\hline Total & $2,361(100)$ & $470(19.9)$ & $720(30.5)$ & 515 (21.8) & $\begin{array}{c}276 \\
(11.7)\end{array}$ & $380(16.1)$ & - & - \\
\hline
\end{tabular}

the traditional 4-year bachelor of pharmacy program, in which $73.5 \%$ of graduates were engaged in community pharmacy, only $19.9 \%$ of 6-year PharmD programme students preferred community pharmacy. Furthermore, their career goals were relatively evenly distributed across diverse career paths, with $30.5 \%$ of students preferring hospital pharmacy, followed by thepharmaceutical industry $(21.8 \%)$, community pharmacy $(19.9 \%)$, further education $(16.1 \%)$,and the government sector (11.7\%). With the introduction of clinical pharmacy and social and administrative pharmacy in the 6-year PharmD program, areas such as pharmaceutical policy, pharmacoeconomics, and pharma coepidemiology have been newly introduced; therefore, it has been proposed that more students will pursue careers in a hospital pharmacy, the government sector or pharmaceutical industry. Although further study is needed to validate this hypothesis, our analysis demonstrated that the new curriculum might be related to diverse career preferences.

Because local community pharmacies are reported to be oversupplied and because the pharmacist surplus is expected to be aggravated due to the increase in the number of pharmacy schools from 20 in 2009 to 35 in 2011 with the introduction of the 6-year PharmD 


\begin{tabular}{|c|c|c|c|c|c|c|}
\hline \multirow[b]{2}{*}{ Characteristics } & \multicolumn{5}{|c|}{ No. of Students (\%) } & \multirow[b]{2}{*}{ P-value ${ }^{a}$} \\
\hline & $\begin{array}{l}\text { Community } \\
\text { Pharmacy }\end{array}$ & Hospital & $\begin{array}{l}\text { Pharmaceutical } \\
\text { Industry }\end{array}$ & Public Sector & $\begin{array}{l}\text { Further } \\
\text { Education }\end{array}$ & \\
\hline $\begin{array}{l}\text { Opportunities for learning } \\
\text { and development }\end{array}$ & $71(15.1)$ & $147(20.4)$ & $141(27.4)$ & $66(23.9)$ & $72(18.9)$ & \multirow{6}{*}{$<0.0001$} \\
\hline Competitive salary & $209(44.5)$ & $110(15.3)$ & $94(18.3)$ & $34(12.3)$ & $41(10.8)$ & \\
\hline Friendly work environment & $40(8.5)$ & $83(11.5)$ & $38(7.4)$ & $26(9.4)$ & $15(3.9)$ & \\
\hline Comprehensive benefit & $11(2.3)$ & $79(11.0)$ & $36(7.0)$ & $40(14.5)$ & $15(3.9)$ & \\
\hline Student's aptitude & $97(20.6)$ & $262(36.4)$ & $193(37.5)$ & $104(37.7)$ & $222(58.4)$ & \\
\hline Others & $42(8.9)$ & $39(5.4)$ & $13(2.5)$ & $6(2.2)$ & $15(3.9)$ & \\
\hline Total & $470(100.0)$ & $720(100.0)$ & $515(100.0)$ & $276(100.0)$ & $380(100.0)$ & - \\
\hline
\end{tabular}

${ }^{a}$ Estimated based on a $\chi 2$ test, with degrees of freedom $=20$

$\%$ Represents the proportion of students.

program $^{8}$, the diverse career preference observed in our analysis was surprising. However, because of the situation in the US, which experienced a $60 \%$ increase in the number of pharmacy schools since $2000,{ }^{9}$ creating and expanding the pharmacist's job beyond dispensing service is critical..$^{15}$ Moreover, academia should actively encourage pharmacy students to diversify their career options, to areas other than community pharmacy, such as the government sectoror pharmaceutical industry. ${ }^{16}$

Interestingly, the demographic characteristics of respondents were significantly associated with the choice of career. Respondents aged 30 and older strongly preferred community pharmacy (64.1\%), which could be explained by the presumed preference of Korean institutions (hospitals, pharmaceutical industry, and government sector) towards younger candidates. Compared to respondents aged 19-24, older respondents wereless likely to pursue further education ( $19.5 \%$ vs. $1.1 \%$, respectively), which is consistent with a previous study. ${ }^{12}$

Respondents located in the Seoul metropolitan area (Seoul/Kyungki province) showed a high preference towards the hospital pharmacy $(28.9 \%)$ and pharmaceutical industry $(26.0 \%)$, whereas community pharmacy and hospital pharmacy were highly preferred by respondents located in the Jeolla/Gyeongsang provinces. Because most pharmaceutical companies are located in the Seoul Metropolitan area, whereas teaching hospitals are located nationwide, it is not surprising that geographic variation was observed in our analysis.

A wide gender divergence was observed in our analysis. This study found that females prefer hospital pharmacy the most (38.3\%) and further education the least $(11.7 \%)$, whereas males prefer community pharmacy the most $(29.3 \%)$ followed by further education $(24.3 \%)$. Almost $50 \%$ of male students who chose community pharmacy as the most preferred career after graduation selected competitive salary (financial reward) as the most significant factor influencing their choice (data not shown) and because community pharmacy usually pays a competitive staring salary compared to other career, ${ }^{17}$ it is reasonable that the community pharmacy is most preferred by male students. However, this study showed that aptitude was considered the most influential factor for those respondents who chose the pharmaceutical industry, government sector, or further education, suggesting that financial reward is not the only critical factor in determining the future career path. This study result is consistent with previous studies, which suggested that job satisfaction plays a critical role in determining the career preference for pharmacy graduates. ${ }^{10,18}$

This study showed that $16.1 \%$ of students desired further education, which is much lower than that reported by an American study(34\%); ${ }^{12}$ however, the intent to seek further education varies significantly based on the student's intrinsic factors, such as age and gender, as well as acquired (extrinsic) factors, such as the year in the pharmacy programme. Specifically, the interest of pursuing further degree(s) decreased as the student's programme year advances, which is the acquired (educational) factor. This trend may be ascribed to the escalating academic rigors of the PharmD curriculum, resulting in a decrease of students who seek further study. Or, because their intention to seek further degrees decreased from $21.7 \%$ to $16.6 \%$ after they had nearly finished pharmacy school, the current PharmD curriculum has not motivated students to seek further education. Because the PharmD curriculum includes a practicum/internship, which comprises 400 hours at a hospital pharmacy, 200 hours at a community pharmacy, 120 hours at a pharmaceutical industry focusing on manufacturing, and 20 hours in the public 


\begin{tabular}{|c|c|c|c|c|c|c|c|}
\hline \multirow{2}{*}{$\begin{array}{l}\text { Military } \\
\text { Service }\end{array}$} & \multirow[b]{2}{*}{ Total } & \multicolumn{5}{|c|}{ No. of Students (\%) } & \multirow[b]{2}{*}{ P-value } \\
\hline & & $\begin{array}{c}\text { Community } \\
\text { Pharmacy }\end{array}$ & Hospital & $\begin{array}{c}\text { Pharmaceutical } \\
\text { Industry }\end{array}$ & $\begin{array}{l}\text { Public } \\
\text { Sector }\end{array}$ & $\begin{array}{l}\text { Further } \\
\text { Education }\end{array}$ & \\
\hline Served & $432(100)$ & $164(38.0)$ & $92(21.3)$ & $97(22.5)$ & $39(9.0)$ & $40(9.3)$ & \multirow[b]{2}{*}{$<0.0001$} \\
\hline $\begin{array}{c}\text { Not } \\
\text { served }\end{array}$ & $395(100)$ & $78(19.7)$ & $41(10.4)$ & $86(21.8)$ & $29(7.3)$ & $161(40.8)$ & \\
\hline
\end{tabular}

aEstimated based on a $\chi^{2}$ tests, with degrees of freedom $=4$.

\section{Supplementary Table 2: Univariate and multivariate logistic regression analysis of demographic characteristics and the likelihood of selecting hospital pharmacy for their future career $(n=2,361)$}

\begin{tabular}{|c|c|c|c|c|}
\hline \multirow{2}{*}{ Characteristics } & \multicolumn{2}{|c|}{ Univariate analysis } & \multicolumn{2}{|c|}{ Multivariate analysis $^{a}$} \\
\hline & OR $(95 \% \mathrm{Cl})$ & $\mathbf{p}$ & OR $(95 \% \mathrm{CI})$ & $\mathbf{p}$ \\
\hline Gender & & $<0.0001$ & & $<0.0001$ \\
\hline Male & Ref & & Ref & \\
\hline Female & $3.234(2.616-3.999)$ & $<0.0001$ & $3.397(2.737-4.216)$ & $<0.0001$ \\
\hline Entrance Age & & 0.0316 & & 0.0008 \\
\hline $19 \leq<25$ & Ref & & Ref & \\
\hline $25 \leq<30$ & $1.195(0.963-1.483)$ & 0.1049 & $1.480(1.179-1.857)$ & 0.0007 \\
\hline $30 \leq$ & $0.605(0.362-1.103)$ & 0.0559 & $0.695(0.410-1.179)$ & 0.1769 \\
\hline Previous Major & & 0.0169 & & \\
\hline Science & Ref & & & \\
\hline Engineering & $0.830(0.675-1.022)$ & 0.0789 & & \\
\hline Health/Medical & $1.432(1.043-1.965)$ & 0.0265 & & \\
\hline Others & $1.016(0.748-1.380)$ & 0.9186 & & \\
\hline Grade & & 0.0311 & & \\
\hline $4^{\text {th }}$ & Ref & & & \\
\hline $3^{\text {rd }}$ & $0.846(0.652-1.097)$ & 0.2063 & & \\
\hline $2^{\text {nd }}$ & $0.731(0.563-0.950)$ & 0.0190 & & \\
\hline $1^{\text {st }}$ & $0.706(0.550-0.907)$ & 0.0065 & & \\
\hline Location of Pharmacy School & & 0.3672 & & \\
\hline Seoul/Kyungi & Ref & & & \\
\hline Gangwon & $1.074(0.678-1.702)$ & 0.7606 & & \\
\hline Chungcheng & $1.235(0.930-1.639)$ & 0.1447 & & \\
\hline Jeolla & $1.060(0.796-1.410)$ & 0.6912 & & \\
\hline Gyeongsang & $1.228(0.977-1.543)$ & 0.0788 & & \\
\hline
\end{tabular}

Multivariate analysis ${ }^{\mathrm{a}}$. Backward selection.

sector, students are less exposed to the need for pursuing further degrees.

Also, the older respondents were less likely to pursue further education as full-time graduate students, which could partly be explained by pressure from their family to be financially independent. However, if we asked other professional degrees, such as masters of business administration or other degrees, which could be obtained part-time, the result may be quite different. ${ }^{12}$ Further efforts emphasizing the importance of continuing education and life-long learning should be provided at pharmacy schools, such as e-learning or multimedia method active learning, ${ }^{19,20}$ which may encourage older students to seek further education.

Electronic questionnaires are inexpensive, easily distributed, and collected; however, their response rate maybe mediocre. Our response rate $(37.3 \%)$ was relatively low, which could introduce non-response bias in our analysis. ${ }^{21}$ Although we took several measures to increase the response rate(provided mobile gift certificates, sent 
reminders a total of 6 times); additional efforts, such as including pictures and shortening questions, could improve the response rate. ${ }^{14}$

Few studies explored 4-year or 6-year pharmacy students' career preference based on a nationally representative sample in Korea. Our study is the first attempt, and it suggests that 6-year PharmD students have diverse career preferences in Korea. However, our study has several limitations. First, it is not clear whether our result could be generalized to all pharmacy students in Korea becausethe underlying population characteristics of pharmacy studentshavenot been reported. The proportion of females, age distribution, or previous major of the population, was also not reported, preventing us from further generalizing our results. Moreover, this study is mainly descriptive; therefore, further study providing motivation behind the career preference is needed. Specifically, whether the career preference is related to the curriculum at the pharmacy school should be examined in future studies. Furthermore, this study examined the "intended" career choice, which should be validated in a future study. Finally, the result should be interpreted with caution because of the low response rate/nonresponse bias. ${ }^{21}$

\section{CONCLUSION}

Unlike the 4-year bachelor of pharmacy programme, in which most graduates are engaged in the community pharmacy, the newly implemented 6-year PharmD students chose the hospital pharmacy as the most preferred career path, followed by the pharmaceutical industry, community pharmacy, further education, and the government sector. Pharmacy students' career preference significantly differs based on their age, gender, geographic location, and previous major. Male respondents had a strong preference towards community pharmacy, and the preference towards the pharmaceutical industry, public sector, and further education decreased with the increase of respondents' age. Because pharmacists are expected to be in oversupply and because community pharmacies are already saturated, continued efforts should encourage pharmacy students to pursue diverse career paths.

\section{ACKNOWLEDGEMENT}

None.

\section{CONFLICTING OF INTEREST}

The author have no conflict of interest to declare.

\section{REFERENCES}

1. Kwon $\mathrm{KH}$. The Strategy of Korean Pharmaceutical Education. Ministry of Education: 2003.

2. The Statistics of Korea Pharmaceutical Association 2012. Korea Pharmaceutical Assocication, 2013.

3. Han AR, Cheon IK, Gil MH, Yang YK, Bae SJ. Analysis of the Pharmaceutical Companies' Recruitment Preference for Bachelor's Degree Holders without Prior Experience. Yakhak Hoeji. 2014;58(6):397-404.

4. Knapp DA. Professionally determined need for pharmacy services in 2020. Am J Pharm Educ. 2002;66(4):421-9.

5. Lee BK. Drug and Therapeutics Professor Status in Korea. Korean J Pharm Policy Res. 2013;8(2):124-35.

6. Gerard K, Tinelli M, Latter S, Blenkinsopp A, Smith A. Valuing the Extended Role of Prescribing Pharmacist in General Practice: Results from a Discrete Choice Experiment. Value in Health. 2012;15(5):699-707. http://dx.doi. org/10.1016/j.jval.2012.02.006; PMid:22867779

7. Anderson Jr DC, Sheffield MC, Hill AM, Cobb HH. Influences on pharmacy students' decision to pursue a doctor of pharmacy degree. Am J Pharm Educ. 2008;72(2). http://dx.doi.org/10.5688/aj720222.

8. Park NY, Choi GE. Current State of Pharmacy Schools in Korea. Korean J Pharm Policy Res. 2011.

9. Brown DL. A Looming Joblessness Crisis for New Pharmacy Graduates and the Implications It Holds for the Academy. Am J Pharm Educ. 2013;77(5):Article 90.

10. Keshishian F. Factors influencing pharmacy students' choice of major and its relationship to anticipatory socialization. Am J Pharm Educ. 2010;74(4). http://dx.doi.org/10.5688/aj740475.

11. Seston E, Hassell K, Ferguson J, Hann M. Exploring the relationship between pharmacists' job satisfaction, intention to quit the profession, and actual quitting. Res Soc Admin Pharm. 2009;5(2):121-32. http://dx.doi. org/10.1016/j.sapharm.2008.08.002 ; PMid:19524860.

12. Migliore MM, Costantino RC, Jr NAC, Albers DS. Educational and career goals of pharmacy students upon graduation. Am J Pharm Educ. 2013;77(9). http:// dx.doi.org/10.5688/ajpe779187 ; PMid:24249849 PMCid:PMC3831398.

13. Ahmad A, Atique S, Balkrishnan R, Patel I. Pharmacy profession in India: Current scenario and Recommendations. Indian J Pharm Educ Res. 2014;48(3):12-15. http://dx.doi.org/10.5530/ijper.48.3.3.

14. Edwards PJ, Roberts I, Clarke MJ, DiGuiseppi C, Wentz R, Kwan I, et al. Methods to increase response to postal and electronic questionnaires (Review). Cochrane database of systematic reviews. 2009;3:1-12. http:// dx.doi.org/10.1002/14651858.mr000008.pub4

15. Frenk J, Chen L, Bhutta ZA, Cohen J, Crisp N, Evans T, et al. Health professionals for a new century: transforming education to strengthen health systems in an interdependent world. The Lancet. 2010;376(9756):19231958. http://dx.doi.org/10.1016/S0140-6736(10)61854-5

16. Ahmad A, Khan MU, Nagappa AN, Patel I. Emerging Job Opportunities for PharmD Graduates: Looking Outside the Box. Indian J Pharm Educ Res. 2014;48(4):6-10. http://dx.doi.org/10.5530/ijper.48.4.2.

17. Polgreen LA, Mott DA, Doucette WR. An examination of pharmacists' labor supply and wages. Res Soc Admin Pharm. 2011;7(4):406-14. http://dx.doi. org/10.1016/j.sapharm.2010.10.006; PMid:21272539.

18. Savage LM, Beall JW, Woolley TW. Factors That Influence the Career Goals of Pharmacy Students. Am J Pharm Educ. 2009;73(2):Article 28. http:// dx.doi.org/10.5688/aj730228 ; PMid:19513167 PMCid:PMC2690887.

19. Azhari FA, Ming LC. Review of e-learning Practice at the Tertiary Education level in Malaysia. Indian J Pharm Educ Res. 2015;49(4):248-57. http://dx.doi. org/10.5530/ijper.49.4.2.

20. Herdeiro MT, DaCruzeSilva O. Multi-method Active Learning Approach: improving the educational experience in Pharmaceutical Drug Development. Indian J Pharm Educ Res. 2014;48(3):16-25. http://dx.doi.org/10.5530/ ijper.48.3.4.

21. Marcano Belisario JS, Jamsek J, Huckvale K, O'Donoghue J, Morrison CP, Car J. Comparison of self-administered survey questionnaire responses collected using mobile apps versus other methods. Cochrane Database Syst Rev. 2015;7. http://dx.doi.org/10.1002/14651858.mr000042.pub2. 